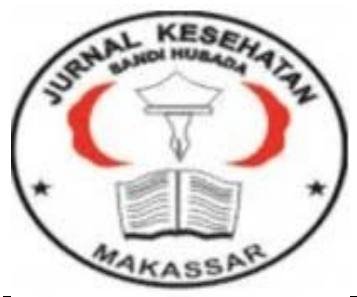

\author{
Jurnal Ilmiah Kesehatan Sandi Husada \\ hhttps://akper-sandikarsa.e-journal.id/JIKSH
}

Vol 11, No, 1, Juni 2020, pp;413-422

p-ISSN: 2354-6093 dan e-ISSN: 2654-4563

DOI: $10.35816 /$ jiskh.v10i2.317

\title{
Hubungan Pengetahuan Perawat Tentang NEWSS dengan Penerapannya
}

Relationship between Nurses' Knowledge about NEWSS and its Application

Fransiska Anita Ekawati' ${ }^{1}$ Miftahul Jannah Saleh ${ }^{2}$, Alisyah Sri Astuti ${ }^{3}$

${ }^{123}$ Keperawatan Medikal Bedah, STIK Stella Maris Makassar

\section{Artikel info}

Artikel history:

Received; 13 April 2020

Revised: 13 Mei 2020

Accepted; 15 Juni 2020

\begin{abstract}
Abstrak.
National Early Warning System Scoring (NEWSS) adalah sebuah pendekatan sistematis yang menggunakan skoring untuk mengidentifikasi perubahan atau perburukan kondisi seseorang sekaligus menjadi standarisasi dalam perawatan sehingga perawat mampu menentukan langkah selanjutnya yang harus dikerjakan. Keterlambatan dalam pencegahan perburukan pasien yang dirawat inap menyebabkan pengaktifan code blue yang bisa disebabkan oleh beberapa faktor salah satunya karena kurangnya pengetahuan perawat tentang NEWSS sehingga mempengaruhi perawat dalam menerapkan protokol NEWSS. Penelitian ini bertujuan untuk mengetahui hubungan antara pengetahuan perawat tentang NEWSS dengan penerapannya. Jenis penelitian ini adalah observasional analitik dengan desain penelitian cross sectional. Metode pengambilan sampel menggunakan teknik probability sampling melalui proportional random sampling yang berjumlah 66 responden. Instrument yang digunakan adalah berupa kuesioner, uji yang digunakan dalam penelitian ini adalah uji statistik chi-square, nilai $p=0,083$ yang dibaca pada analysis continuity correction. Hal ini menunjukkan bahwa $p(0,083)>\alpha(0,05)$ sehingga tidak ada hubungan pengetahuan perawat tentang NEWSS dengan penerapannya di ruang rawat inap Rumah Sakit Swasta Makassar. Diharapkan bagi Institusi untuk meningkatkan supervisi, sehingga perawat tahu dan mampu menerapkan protokol NEWSS.
\end{abstract}

\footnotetext{
Abstract.

National Early Warning System Scoring (NEWSS) is a systematic approach that uses scoring to identify changes or worsening conditions of a person as well as being standardized in care so that nurses are able to determine the next step that must be done. Delay in the prevention of worsening of hospitalized patients causes the activation of
} 
code blue which can be caused by several factors, one of which is due to the lack of nurses' knowledge of NEWSS, thus affecting nurses in implementing the NEWSS protocol. This study aims to determine the relationship between nurses' knowledge about NEWSS and its application. This type of research is analytic observational with cross sectional research design. The sampling method uses probability sampling technique through proportional random sampling, amounting to 66 respondents. The instrument used was in the form of a questionnaire, the test used in this study was the chisquare statistical test, the value of $p=0.083$ which was read in analysis continuity correction. This shows that $p(0.083)>\alpha$ (0.05) so that there is no relationship between nurses' knowledge about NEWSS and its application in the inpatient room at Swasta Hospital Makassar. It is expected that Institutions will increase supervision, so that nurses know and are able to implement the NEWSS protocol.

Keywords:

Pengetahuan

Perawat;

NEWSS;

Penerapan NEWSS
Coresponden author:

Email: fransiskaanitarahayu@gmail.com

artikel dengan akses terbuka dibawah lisensi BCC BY NC ND-4.0

\section{Pendahuluan}

Keberhasilan pertolongan terhadap kegawatan pasien sangat tergantung dari kecepatan dan ketepatan dalam melakukan pengkajian awal yang akan menentukan keberhasilan asuhan keperawatan pada sistem kegawatan pasien. Kegawatdaruratan dapat terjadi tidak hanya pada saat pasien masuk di rumah sakit, namun dapat terjadi ketika pasien sedang dalam perawatan di rumah sakit. Oleh karena itu, perawat sebaiknya mengenali perubahan kondisi klinis pasien di ruang rawat inap Rumah Sakit yang dapat mengakibatkan kejadian yang tidak diharapkan diantaranya, yaitu pemindahan pasien yang tidak direncanakan ke unit perawatan intensif karena henti jantung (cardiac arrest, henti nafas (apneu) dan kematian) (Zuhri \& Nuramalia, 2018).

Menurut Fennessy dalam Subhan, Giwangkencana, Prihartono, \& Tavianto (2019), angka kejadian henti jantung di Rumah Sakit sangat bervariasi di dunia, berkisar antara 0,5 hingga 2\%. Studi yang dilakukan di Australia dan New Zealend menunjukkan angka kejadian henti jantung di Rumah Sakit berkisar 2-6 kasus per 1.000 admisi. Di Amerika Serikat kejadian henti jantung atau In Hospital cardiac Arrest (IHCA) mencapai 200.000 kasus setiap tahunnya. Menurut Indonesian Heart Association (IHA), penyakit kardiovaskular menjadi salah satu penyebab terjadinya kejadian henti jantung. Henti jantung adalah hilangnya fungsi jantung untuk memompa darah yang terjadi secara mendadak (Dame, Kumaat, \& Laihad, 2017).

Menurut Duncan \& McMullan (2012), penanganan henti jantung di rumah sakit meliputi pengawasan dan pencegahan terhadap henti jantung, aktivasi sistem gawat darurat, resusitasi jantung paru segera, defibrilasi segera dan penanganan pasca henti jantung yang terintegrasi. Sebagian besar pasien yang mengalami gagal jantung atau gagal paru sebelumnya memperlihatkan tanda-tanda fisiologis diluar kisaran normal, yang merupakan indikasi keadaan pasien memburuk (Zuhri \& Nuramalia, 2018). Oleh karena itu, upaya pengawasan dan pencegahan terhadap henti jantung di ruang rawat inap 
Rumah Sakit salah satunya adalah meningkatkan kemampuan perawat dalam memonitor perubahan kondisi pasien yang memburuk, serta mampu melakukan tindakan yang tepat, terutama pada perawat yang bekerja di luar ruang Intensif Care Unit (ICU) dan ruang Instalasi Gawat Darurat (IGD). Maka, Perawat yang bekerja diluar area pelayanan kritis atau intensif (ruang ICU dan IGD) perlu dibekali pengetahuan dan pelatihan yang cukup untuk melakukan asesmen agar mengetahui pasien yang akan masuk dalam kondisi kritis. Karena banyak pasien di luar area pelayanan kritis mengalami keadaan kritis selama dirawat inap dan tidak teridentifikasi sehingga bisa berakibat kepada kematian.

Namun permasalahan yang sering ada di ruang rawat inap yaitu perawat melakukan pengukuran tanda-tanda vital (TTV) tidak secara konsisten sesuai waktunya atau berdasarkan rutinitas, maupun dalam pendokumentasian, serta tidak mampu menganalisis hasilnya sehingga tidak melaksanakan penanganan segera dari respon perubahan klinis pasien yang merupakan indikasi keadaan pasien memburuk. Perawat yang tidak mampu berpikir kritis atau tidak mampu menganalisis perubahan kondisi fisiologis pasien akan meningkatkan angka kejadian code blue. Untuk itu Rumah Sakit perlu mengetahui adanya mekanisme untuk meningkatkan pemantauan atau monitor perubahan kondisi pasien seperti TTV. Parameter ini untuk menilai fungsi fisiologis sebagai dasar untuk menentukan tindakan keperawatan lebih lanjut. Berdasarkan hal ini maka perlu adanya suatu mekanisme mutu pemantauan TTV terutama dalam menginterpretasikan dan tindak lanjut terhadap hasil monitoring yaitu Early Warning System (EWS) (Duncan \& McMullan, 2012).

EWS adalah suatu sistem permintaan bantuan untuk mengatasi masalah kesehatan pasien secara dini. EWS didasarkan atas penilaian terhadap perubahan keadaan pasien melalui pengamatan yang sistematis terhadap semua perubahan fisiologis pasien. Sistem ini merupakan konsep pendekatan proaktif untuk meningkatkan keselamatan pasien dan hasil klinis pasien yang lebih baik dengan standarisasi pendekatan asesmen dan menetapkan skoring parameter fisiologis yang sederhana. EWS adalah sebuah sistem skoring fisiologis yang umumnya digunakan di unit medikal bedah sebelum pasien mengalami kondisi kegawatan. Skoring EWS disertai dengan algoritme tindakan berdasarkan hasil skoring dari pengkajian pasien. Parameter dalam metode EWS yaitu tingkat kesadaran, respirasi atau pernafasan, saturasi oksigen, oksigen tambahan, suhu, denyut nadi, dan tekanan darah sistolik (Duncan \& McMullan, 2012).

Meningkatnya skor EWS mengindikasikan memburuknya pasien dan dengan demikian itu juga digunakan untuk memilih pasien yang mungkin mendapat manfaat dari tingkat perawatan yang lebih tinggi, seperti unit perawatan intensif (ICU) atau penerimaan unit ketergantungan tinggi. Salah satu jenis EWS yang dikembangkan di beberapa Rumah Sakit saat ini adalah National Early Warning Scoring System (NEWSS). NEWSS adalah sebuah system skoring fisiologis (TTV) yang umumnya digunakan di unit medikal bedah sebelum pasien mengalami kondisi kegawatan. Skoring NEWSS disertai dengan algoritme tindakan berdasarkan hasil skoring dari pengkajian pasien. NEWSS melengkapi sistem tim medis reaksi cepat, dalam menangani kondisi kegawatan pada pasien atau biasa kita kenal dengan code blue (Duncan \& McMullan, 2012).

Perawat sebagai lini terdepan yang selama 24 jam selalu bersama pasien, perlu dilatih untuk mendeteksi atau mengenali perubahan kondisi pasien yang memburuk, serta mampu melakukan tindakan keperawatan yang tepat. Untuk meningkatkan pengetahuan perawat sehingga mampu mengaplikasikan pengkajian NEWSS untuk mencegah terjadinya kondisi kegawatdaruratan, biasanya Rumah Sakit telah melakukan pelatihan tentang NEWSS sesuai dengan kebijakan Rumah Sakit masing-masing agar seluruh 
perawat dirumah sakit sudah tahu dan paham dalam menerapkan NEWSS. Keberhasilan EWS dalam menurunkan angka kejadian henti jantung dipengaruhi oleh implementasi yang baik dari instrumen EWS sesuai dengan pedoman yang ditetapkan (Subhan, Giwangkencana, Prihartono, \& Tavianto, 2019).

Berdasarkan pengamatan peneliti, dari 10 perawat yang berada diruang rawat inap mengatakan sulit untuk menerapkan NEWSS karena merasa masih baru dengan ilmu ini dan masih dalam proses belajar menerapkan, ada beberapa perawat yang mengatakan kejadian code blue terjadi secara tiba-tiba tanpa ada perubahan kondisi fisiologis pasien, ada juga yang mengatakan perawat sudah melakukan NEWSS namun belum ada instruksi untuk dilakukan pemindahan ke ruangan ICU, ada juga yang mengatakan terkadang keluarga pasien menolak untuk dilakukan pemindahan pasien ke ruang ICU, ada juga yang berpendapat bahwa NEWSS itu digunakan hanya pada pasien gawat atau kritis, serta tingginya beban kerja terhadap pendokumentasian juga ikut mempengaruhi penerapan NEWSS itu sendiri, sehingga angka kejadian henti jantung di ruang rawat inap belum mengalami penurunan karna keterlambatan dalam mengenal perubahan kondisi fisiologis pasien.

Dari latar belakang di atas, menunjukkan pentingnya NEWSS untuk diterapkan, sehingga sangat dibutuhkan pengetahuan perawat dalam penerapan NEWSS. Maka dari itu, peneliti sangat tertarik untuk meneliti apakah ada hubungan antara pengetahuan perawat dengan penerapan NEWSS.

\section{Metode}

Penelitian ini menggunakan jenis penelitian obsevasional analitik dengan desain penelitian cross sectional. Penelitian dilakukan di salah satu RS swasta di Makassar, Provinsi Sulawesi Selatan. Penelitian dilaksanakan pada bulan Januari sampai dengan February 2020. Pengambilan sampel dilakukan dengan teknik probability sampling dengan cara Proportional Random sampling. Sampel dalam penelitian ini berjumlah 66 responden dengan kriteria perawat yang bekerja di ruangan perawatan, bersedia sebagai responden. Instrumen yang digunakan dalam penelitian ini adalah kuesioner Pengetahuan tentang NEWSS terdiri dari 9 pertanyaan dan kuesioner Penerapan NEWSS terdiri dari 16 pertanyaan. Kuesioner tentang pengetahuan dan penerapan NEWSS telah dilakukan uji cronbach's $\alpha$ 0,90 dan uji validitas $r=0,803$ dan $\mathrm{p}<0,001$.

Pengambilan data responden sesuai dengan kriteria inkulsi, dimana dilakukan pada perawat yang bekerja di unit perawatan, sebelum mengisi kusioner diberikan penjelasan terlebih dahulu, tentang tujuan, manfaat, prosedur penelitian serta risikonya. Persetujuan pengisian kusioner diperoleh atas dasar sukarela. Karena penelitian ini hanya melibatkan pengumpulan informasi, tidak ada risiko yang berat yang akan berdampak langsung kepada responden. Jika responden tidak setuju makan dapat menolak untuk ikut dalam penelitian ini. Namun, peserta dijelaskan bahwa informasi yag diberikan dapat membantu peneliti untuk merencanakan strategi yang efektif untuk perawatan pasien stroke dan memajukan profesi keperawatan. Untuk memastikan kerahasiaan, peneliti memberikan kode untuk setiap kuisoner dan menginterpretasi hasil kedua kuioner dan dicatat dalam formulir kusioner lalu dimasukan dalam amplop, dan kemudian disegel. 


\section{Hasil Dan Pembahasan}

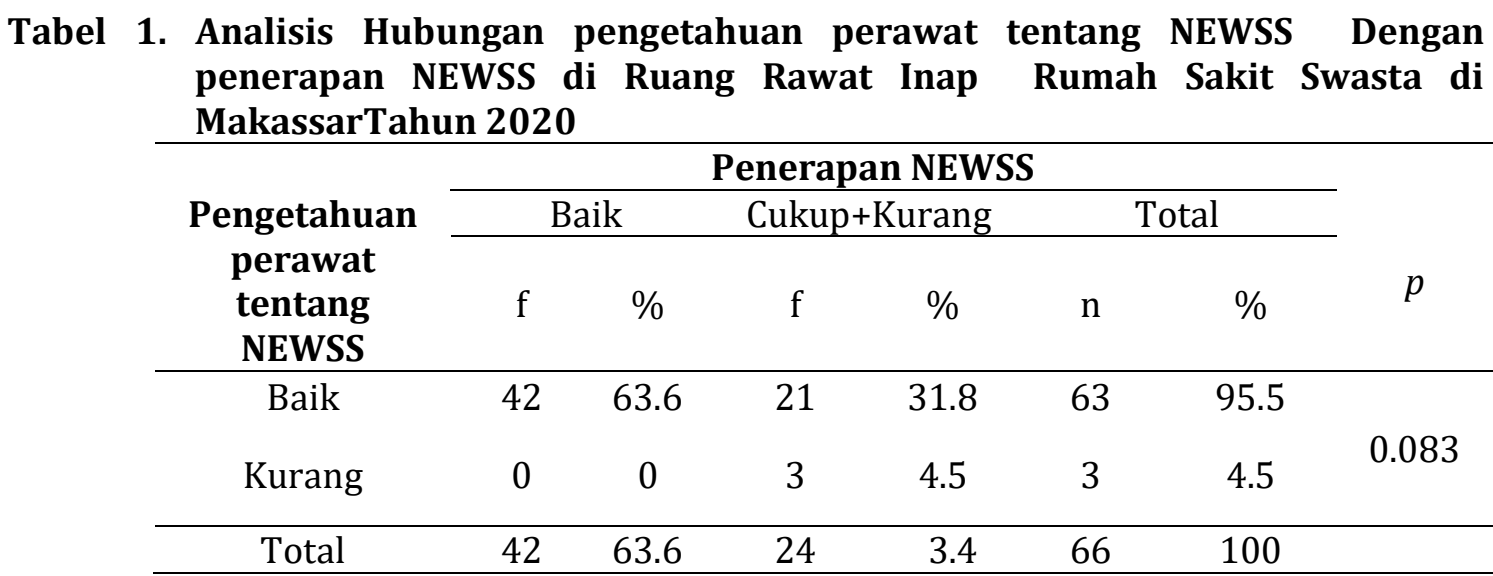

Analisis Continuity Correction

Berdasarkan hasil uji statistik pada tabel 4 dengan menggunakan uji chi square tabel $2 \times 3$ tidak dapat di baca pada fisher's exact test karena tidak terpenuhi maka dilanjutkan dengan penggabungan sel. Sehingga ukuran tabel menjadi $2 \times 2$. Penelitian dengan jumlah responden 66 tabel $2 \times 2$ maka hasil uji statistic di baca di Continuity Correction, diperoleh nilai $p=0,083$ dimana nilai $\alpha=0,05$. Hal ini menunjukkan bahwa nilai $p(0,083)>\alpha(0,05)$, maka hipotesis nol (Ho) diterima dan hipotesis alternatif ( $\mathrm{Ha}$ ) ditolak, hal ini menunjukan bahwa tidak ada hubungan antara pengetahuan perawat tentang NEWSS dengan penerapan NEWSS di ruang rawat inap Rumah Sakit Swasta Makassar.

Berdasarkan hasil penelitian yang dilakukan oleh peneliti di salah satu Rumah Sakit Swasta di Makassar, didapatkan $63(95,5 \%)$ dari 66 responden memiliki pengetahuan yang baik, dan $3(4,5 \%)$ responden berpengetahuan kurang, sehingga dari hasil tersebut dapat disimpulkan bahwa sebagian besar responden memiliki pengetahuan yang baik tentang NEWSS.

Menurut teori dari (Saragih \& Rumapea, 2011) upaya untuk meningkatkan pengetahuan dengan memberikan kesadaran melalui kegiatan yang disebut penyuluhan kesehatan. Sehingga dengan pengetahuannya akan menimbulkan sikap dan akhirnya menyebabkan individu atau kelompok akan berperilaku yang didasarkan pada kesadaran dan kemauan individu yang bersangkutan. Pengetahuan secara kolektif adalah kumpulan informasi yang dimiliki oleh seseorang atau kelompok, atau budaya tertentu. Sedangkan secara umum pengetahuan adalah komponen-komponen mental yang dihasilkan dari semua proses apapun, entah lahir dari bawaan atau dicapai lewat pengalaman. (Reber \& Emile, 2010).

Hal ini yang telah dilakukan ditempat penelitian yaitu memberikan sosialisasi atau pelatihan tentang NEWSS untuk meningkatkan pengetahuan para perawat yang bekerja di tempat penelitian sehingga perawat dapat menjalankan perannya dengan professional. Keperawatan sebagai profesi merupakan salah satu pekerjaan dimana dalam menentukan tindakannya didasari pada ilmu pengetahuan serta memiliki keterampilan yang jelas dalam keahliannya, selain itu sebagai profesi keperawatan mempunyai otonomi dalam kewenangan dan tanggung jawab dalam tindakannya serta adanya kode etik dalam bekerja kemudian juga berorientasi pada pelayanan melalui pemberian asuhan keperawatan kepada individu, kelompok, atau masyarakat. (Hidayat, 2004). 
Menurut asumsi peneliti, upaya untuk pengembangan professional perawat adalah dengan melakukan pelatihan atau inhouse training sebagai salah satu upaya meningkatkan pengetahuan perawat yang sementara bekerja diluar lingkup pendidikan (kampus/institusi/perguruan tinggi). Sehingga dapat disimpulkan tingkat pengetahuan perawat dalam penilaian NEWSS berada pada tingkat baik, hal ini juga terlihat pada distribusi data frekuensi masa kerja sebanyak 45 (68.2\%) responden dalam kurung waktu $<5$ tahun, data ini menunjukkan mayoritas responden masih fresh graduate sehingga masih semangat untuk mendapatkan ilmu atau pengetahuan baru.

\section{Penerapan Perawat terhadap NEWSS}

Berdasarkan hasil penelitian yang dilakukan oleh peneliti di Rumah Sakit Swasta Makassar, didapatkan 42 (63.6\%) responden memiliki penerapan yang baik, 23 (34.8\%) responden memiliki penerapan yang cukup, dan ada $1(1.5 \%)$ responden yang kurang menerapkan NEWSS sesuai SOP. Sehingga dari hasil tersebut dapat disimpulkan bahwa sebagian besar responden memiliki penerapan yang baik terhadap protokol NEWSS namun masih ada beberapa perawat yang belum menerapkan NEWSS sesuai SOP. Dimana hasil wawancara dengan perawat didapatkan faktor yang menyebabkan ketidakpatuhan dalam menerapkan NEWSS sesuai SOP adalah aktivitas yang terlalu banyak, pasien yang banyak, pendokumentasian yang terlalu banyak dan mengira bahwa pasien masih dalam kondisi yang stabil.

Dilihat dari distribusi data masa kerja responden, mayoritas masa kerja $<5$ tahun ada 45 $(68,2 \%)$ dari 66 responden sehingga insting dan pengalaman kerja masih kurang. Hal ini sejalan dengan teori (Agus \& Budiman, 2014) yang menyatakan bahwa pengalaman sebagai sumber pengetahuan adalah suatu cara untuk memperoleh kebenaran pengetahuan dengan cara mengulang kembali pengetahuan yang diperoleh dalam memecahkan masalah yang dihadapi masa lalu. Pengalaman belajar dalam bekerja yang dikembangkan akan memberikan pengetahuan dan keterampilan professional, serta dapat mengembangkan kemampuan mengambil keputusan yang merupakan manifestasi dari keterpaduan menalar secara ilmiah dan etik yang bertolak dari masalah nyata dalam bidang kerjanya.

Berdasarkan asumsi peneliti, penerapan NEWSS yang dilakukan responden di dasari atas pengetahuan yang baik dan di dukung oleh pelatihan ulang tentang NEWSS yang telah dilakukan oleh pihak Rumah Sakit Swasta . Adapun beberapa responden yang dalam penerapannya masih dalam kategori cukup + kurang dikarenakan tingginya beban kerja yang dialami oleh responden dan keterbatasan pengalaman karena lama kerja mayoritas kurang dari 5 tahun.

\section{Hubungan Pengetahuan dan Penerapan Perawat terhadap NEWSS}

Berdasarkan hasil penelitian yang telah dianalisis menggunakan uji chi square dan hasilnya dibaca dalam continuity correction, dimana nilai $p=0,083$ dan nilai $\alpha=0,05$. Maka dapat disimpulkan nilai $p>\alpha$, dimana hipotesis alternatif (Ha) ditolak dan hipotesis nol (Ho) diterima. Hal ini menunjukkan bahwa tidak ada hubungan antara pengetahuan perawat tentang NEWSS dengan penerapannya di ruang rawat inap Rumah Sakit Swasta Makassar, yang berarti walaupun perawat berpengetahuan baik namun belum bisa mempengaruhi penerapan NEWSS di ruangan rawat inap.

Hal lain yang bisa mendukung dapat dilihat pada sel yang didapatkan ada 21 (31,8\%) dari 66 responden yang memiliki pengetahuan baik dengan penerapan cukup kurang yang menyebabkan penerapan NEWSS masih ada yang belum sesuai. Hal ini disebabkan karena beberapa responden melakukan pengisian protokol NEWSS hanya jika pasien 
mengeluhkan keluhannya, ada juga yang mengisi protokol NEWSS tapi mengacuhkan hasil dari skoring NEWSS tersebut dan tidak melakukan skoring NEWSS pada pasien dengan kondisi yang stabil. Oleh karena itu pengetahuan tidak selamanya mempengaruhi penerapan. Karena ada ada beberapa faktor yang mempengaruhi penerapan salah satunya adalah supervisi. Dimana dapat dilihat pada penelitian (Widjayanti, 2012) yang menyatakan bahwa supervisi berkontribusi dalam melaksanakan pendokumentasian asuhan keperawatan. Sehingga supervisi berhubungan dengan pendokumentasian asuhan keperawatan. Hasil penelitian ini juga sesuai dengan penelitian terdahulu Aripin dalam (Sudarmo, Helmi, \& Marlinae, 2016) yang menyatakan bahwa responden yang mendapatkan dukungan pengawasan dari pimpinannya berpeluang lebih patuh sebesar 21 kali dibandingkan dengan responden yang kurang mendapat dukungan pengawasan dari pimpinannya.

Pada penelitian yang telah dilakukan peneliti dilihat dari lama kerja responden mayoritas $<5$ tahun sebanyak $45(68,2 \%)$ dari 66 responden sejalan dengan penelitian yang dilakukan oleh (Pambudi, Sutriningsih, \& Yasin, 2018) dan (Faridah, Ispahani, \& Badriah, 2019) yang menyatakan ada beberapa faktor yang mempengaruhi penerapan perawat dalam menerapkan SKP selain pengetahuan yaitu lama kerja, motivasi, supervisi dan beban kerja. Hal ini yang menyebabkan penerapan juga dipengaruhi oleh pengalaman yang terbukti sejalan dengan penelitian yang dilakukan oleh (Turangan, Kumaat, \& Malara, 2017) juga menunjukkan bahwa tidak terdapat hubungan antara pendidikan dan pelatihan dengan pengetahuan perawat dengan nilai p $0,187(>\alpha 0,05)$, terdapat hubungan yang signifikan nilai $\mathrm{p} 0,001(<\alpha, 0,05)$ antara pengalaman dan pengetahuan perawat dalam menghadapi cardiac arrest, yang di dukung oleh hasil penelitian Widyaningsih (2014) dalam penelitiannya disimpulkan bahwa ada hubungan antara masa kerja, sikap, pengetahuan, beban kerja dengan praktek pendokumentasian asuhan keperawatan perawat pelaksana di Ruang Kenanga dan Anggrek RSUD Tugurejo Semarang.

Tetapi hasil ini tidak sejalan dengan penelitian yang dilakukan oleh (Simanjuntak, 2019) yang menyatakan bahwa terdapat tiga faktor yang mempengaruhi pelaksanaan sasaran keselamatan pasien. Faktor-faktor tersebut adalah tingkat pengetahuan perawat, sikap perawat, dan fasilitas di rumah sakit.

Menurut asumsi peneliti, hal yang menyebabkan responden cukup kurang dalam menerapkan protokol NEWSS adalah sering menganggap perubahan fisiologis pasien hal yang biasa sehingga perlunya resosialisasi atau mengupdate ilmu tentang NEWSS dan supervisi dari kepala ruangan dan memberi teguran jika tidak menjalankan protokol NEWSS. Sehingga para perawat selalu mempunyai rasa peduli dan tanggung jawab terhadap pasien sehingga motivasi kerja menjadi meningkat. Oleh karena itu, dapat disimpulkan bahwa penerapan tidak selamanya dipengaruhi oleh pengetahuan karna ada beberapa faktor yang mempengaruhi penerapan seperti jenis kelamin, keterampilan, beban kerja, motivasi dan superivisi. Berdasarkan wawancara singkat dengan responden mengatakan penerapan NEWSS tidak berjalan sesuai SOP karena ada beban kerja yang cukup tinggi dan kekurangan tenaga, ada juga yang mengatakan telah melaksanakan penerapan NEWSS sesuai prosedur tapi keluarga pasien menolak untuk dilakukan transfer pasien ke ICU dikarenakan ketika pasien berada di ruang ICU, keluarga tidak dapat mendampingi pasien. Selain itu responden terdiri atas mayoritas perawat yang memiliki pengalaman kerja kurang dari 5 tahun yaitu 45 responden (72.7\%), hal ini menunjukkan bahwa dalam menerapkan pengetahuan dalam praktik keperawatan dibutuhkan pengalaman yang terasah melalui kebiasaan dan keterampilan di Rumah Sakit terutama kemampuan berpikir kritis seorang perawat dalam menghadapi situasi atau kondisi 
pasien sehingga mampu mengambil keputusan yang cepat dan tepat saat melakukan asuhan keperawatan, terutama mampu menerapkan NEWSS sehingga dapat mencegah kejadian code blue di ruang perawatan.

Selain itu berdasarkan penelitian didapatkan dari 66 responden terdapat 42 (63.6\%) responden yang mempunyai pengetahuan yang baik tentang NEWSS dengan penerapan yang baik. Pengetahuan merupakan kemampuan seseorang yang berada pada kawasan kognitif yang dapat dikembangkan melalui proses pendidikan-belajar. Ini juga sejalan dengan teori (Notoadmojo, 2010) yang menyatakan bahwa pengetahuan berbanding lurus dengan penerapan atau pengaplikasian. Perawat perlu untuk meningkatkan pengetahuan perawat untuk memperbaiki kinerjanya dapat dilakukan dengan beberapa cara yaitu dengan sosialisasi, pelatihan berkelanjutan, dan belajar ke jenjang pendidikan yang lebih tinggi. Melalui tindakan dan belajar, seseorang akan bertambah kepercayaan dirinya dan berani mengambil sikap terhadap sesuatu yang akhirnya akan mempengaruhi perilaku

Menurut peneliti, sebaiknya pengetahuan sejalan dengan penerapan sesuai dengan teori (Notoadmojo, 2010) yang menyatakan bahwa pengetahuan berbanding lurus dengan penerapan atau pengaplikasian. Oleh karena itu sangat dibutuhkan supervisi dari kepala ruangan, atau kepala bidang keperawatan untuk menstimulus atau merangsang sensitivitas perawat menerapkan apa yang sudah diketahuinya, terutama bila Rumah Sakit telah berupaya mengembangkan profesionalitas perawatnya dengan rutin mengadakan pelatihan tentang ilmu-ilmu terbaru dalam kegawatdaruratan. Selain itu dibutuhkan kemampuan berpikir kritis seorang perawat dalam melakukan asuhan keperawatan sehingga mampu dengan tepat melakukan intervensi keperawatan sesuai dengan masalah yang dihadapi oleh pasien. Maka perawat harusnya mampu menerapkan apa yang telah diketahuinya sehingga dapat berkembang, terutama dalam pelayanan kegawatdaruratan karena perawat merupakan ujung tombak keberhasilan pencegahan terjadinya code blue.

\section{Simpulan Dan Saran}

Dari hasil penelitian yang telah dilakukan terhadap 66 responden Februari 2020 di salah satu Rumah Sakit Swasta di Makassar, maka dapat disimpulkan:

1. Pengetahuan perawat tentang NEWSS dalam kategori baik

2. Penerapan NEWSS sebagian besar dalam kategori baik namun masih ada dalam kategori cukup dan kurang

3. Tidak ada hubungan antara pengetahuan perawat tentang NEWSS dengan penerapan NEWSS di salah satu Rumah Sakit Swasta di Makassar.

Diharapkan hasil dari penelitian ini membuat perawat mengetahui pentingnya NEWSS dan mampu menerapkannya sehingga perburukan perubahan kondisi fisiologis pasien dapat dicegah sebelum menjadi kondisi kegawatdaruratan sehingga menurunkan angka kejadian pengaktifan code blue, juga dapat dijadikan sebagai informasi, bahan masukan dan pembelajaran serta evaluasi, sehingga mampu menetapkan kebijakan bagi Profesional Pemberi Asuhan Keperawatan tentang pentingnya supervisi dan evaluasi penerapan pengkajian NEWSS untuk meningkatkan upaya pencegahan kondisi kegawatdaruratan di ruang perawatan rawat inap.

\section{Daftar Rujukan}

Agus, R., \& Budiman. (2014). Kapita Selekta Kuesioner Pengetahuan dan Sikap Dalam Penelitian Kesehatan. Jakarta: Salemba Medika. 
Alhidayat, N. S., Rahmat, A., \& Simunati. (2013). Hubungan Tingkat Pengetahun Perawat Instalasi Gawat Darurat Tentang Pengkajian Terhadap Pelaksanaan Tindakan Life Support Di Rumah Sakit Pelamonia Makassar.

Ali, H. Z. (2014). Dasar-Dasar Keperawatan Profesional. Jakarta: EGC.

Aripuddin, I. (2014). Ensiklopedia Mini;Asal Mula Profesi Perawat. Jakarta: Angkasa.

Badudu, \& Zain, S. M. (2010). Efektifitas Bahasa Indonesia. Jakarta: Balai Pustaka.

Bagolz. (2010). Konsep Dasar Keperawatan. Jakarta: EGC.

Dame, R. B., Kumaat, L. T., \& Laihad, M. L. (2017). Gambaran Tingkat Pengetahuan Perawat Tentang Code Blue System di RSUP Prof. Dr. R. D Kandou Manado. Indonesian Heart Association.

Duncan, K., \& McMullan, C. (2012). Early Warning System. Philadelphia: Lippincott Williams \& Wilkins.

Faridah, I., Ispahani, R., \& Badriah, E. L. (2019). 21JurnalIlmiah Kesehatan, Vol. VIIINo. 1 Mei 2019. ISSN 2086-9266faktor-Faktor Yang Mempengaruhi Penerapan Budaya Keselamatan Pasien (Patient Safety Culture) Pada Perawat Di Rawat Inaprsu Kabupaten Tangerang. JurnalIImiah Kesehatan, Vol. VIIINo. 1 Mei 2019. ISSN 20869266.

Firmansyah. (2013). NEWSS: Nursing Early Warning Scoring System RSCM.

Handayani, D., \& Armina. (2017). Faktor-Faktor yang Berhubungan dengan Penerapan Komunikasi Teraupetik Oleh Perawat Pada Pasien di Ruang Rawat Inap Rumah Sakit Umum Daerah Raden Matahher Jambi. Jurnal Akademia Baiturrahim Vol.6 No.2.

Hidayat, A. A. (2004). Pengantar Konsep Dasar Keperawatan. Jakarta: Salemba Medika.

Kamus Besar Bahasa Indonesia . (2014).

Kementerian Kesehatan Republik Indonesia. (2019). Laporan Nasional Riskesdas 2018.

Lestari, T. (2015). Kumpulan Teori Untuk Kajian Pustaka Penelitian Kesehatan. Yogyakarta: Nuha Medika.

Mathuridy, M. R. (2015). Hubungan Umur, Lama Kerja, Pendidikan dan Motivasi dengan Kepatuhan Perawat Melakukan Enam Langkah Lima Momen Cuci Tangan di Ruang ICU RSUD Ulin Banjarmasin. Jurnla Penelitian Sekolah Tinggi Ilmu Kesehatan MUhammadiyah Banjarmasin Volume 3, No.2.

National Clinical Efektiveness Committee. (2013). National Early Warning Score, National Clinical Guideline No.1.

National Heart, Lung and Blood Institute. (2010). Retrieved oktober 2019, from What is Carotid Artery Disease:

http://www.nhlbi.nih.gov/health/healthtopics/topics/cad/.

Nugroho, R. (2003). Prinsip Penerapan Pembelajaran. Jakarta: Balai Pustaka.

Notoadmojo, S. (2010). Ilmu Perilaku Kesehatan. Jakarta: Rineka Cipta.

Pambudi, Y. D., Sutriningsih, A., \& Yasin, D. D. (2018). Faktor-Faktor yang Mempengaruhi Perawat Dalam Penerapan 6 SKP (Sasaran Keselamatan Pasien) pada Akreditasi JCI (Joint Commission International) di Ruang Rawat Inap Rumah Sakit Panti Waluya Malang. Nursing News Volume 3, Nomor 1.

Pongantung, H. (2019). Pedoman Penulisan Skripsi. Sukarta: CV Oase Group.

Potter, P., \& Perry, A. (2009). Buku Ajar Fundamental Keperawatan Konsep, Proses dan Praktik. Jakarta: EGC.

Potter, P. A., \& Perry, A. G. (2010). Buku Ajar Fundamental Keperawatan;Konsep, Proses, dan Praktik. Jakarta: EGC.

Reber, A. S., \& Emile, S. R. (2010). Kamus Psikologi. Yogyakarta: Pustaka Belajar.

Rivai, V., \& Mulyadi, D. (2012). Kepemimpinan dan Perilaku Organisasi. Jakarta: Rajagrafindo Persada. 
Robbin. (2010). Perilaku Organisasi. Jakarta: PT. Indeks Kelompok Gramedia.

Royal College of Physician. (2012). National Early Warning Score (NEWS): Standardising the assessment of acuteillness severity in the NHS.

RS.Swasta . (2018). Panduan Pelaksanaan Early Warning System. Makassar: RS Swasta .

Samsudin, S. (2006). Manajemen Sumber Daya Manusia. Bandung: Pustaka Setia.

Saragih, R., \& Rumapea, N. (2011). Hubungan Karakterisitk Perawat Dengan Tingkat Kepatuhan Perawat Melakukan Cuci Tangan di Rumah Sakit Columbia Asia Medan. Jurnal Ilmu Keperawatan Volume 3, No.1 Tahun 2011. Universitas Darma Agung Medan.

Setiawan, G. (2004). Implementasi Dalam Birokrasi Pembangunan. Jakarta: Balai Pustaka.

Setyorini, F. A., Pratiwi, A., \& Dewi, E. (2011). Hubungan Pengetahuan Perawat dengan Keterampilan Perawat dalam Melaksanakan Resusitasi Jantung Paru di Ruang Kritis dan IGD Rumah Sakit Moewardi Surakarta.

Simanjuntak, E. C. (2019). Faktor Yang Mempengaruhi Pelaksanaan Sasaran Keselamatan Pasien Sebagai Salah Satu Indikator Pelayanan Di Rumah Sakit.

Subhan, N., Giwangkencana, G. W., Prihartono, M. A., \& Tavianto, D. (2019). Implementasi Early Warning Score pada Kejadian Henti Jantung di Ruang Perawatan RSUP Dr. Hasan Sadikin Bandung yang Ditangani Tim Code Blue Selama Tahun 2017. Jurnal Anastesi Perioperatif.

Sucipto. (2019). Mengapa Sistem Code Blue Penting? Retrieved oktober 2019, from http://rsudwonosari.web.id/artikel/view/MENGAPA-SISTEM-CODE-BLUEPENTING_ID64.html

Sudarmo, Helmi, Z. N., \& Marlinae, L. (2016). Faktor Yang Mempengaruhi Perilaku Terhadap Kepatuhan Penggunaan Alat Pelindung Diri Untuk Pencegahan Penyakit Akibat Kerja. Jurnal Berkala Kesehatan Vol.1 No.2.

Turangan, T. S., Kumaat, L. T., \& Malara, R. (2017). Faktor-Faktor yang Berhubungan dengan Pengetahuan Perawat Dalam Menghadapi Cardiac Arrest di RSUP Prof R. D. Kandou Manado.

Undang-Undang Republik Indonesia No.38 Tahun 2014 Tentang Keperawatan. (2014). Jakarta.

Usman, N. (2002). Konteks Implemnetasi Berbasis Kurikulum. Jakarta: Grasindo.

Wahab. (2008). Tujuan Penerapan Program. Jakarta: Bulan Bintang.

Wawan, \& Dewi, W. (2010). Teori dan Pengukuran Pengetahuan, Sikap, dan Perilaku Manusia. Yogyakarta: Nuha Medika.

Widjayanti, T. B. (2012). Hubungan Antara Karakteristik Individu, Psikologi dan Organisasi Denga Prilaku Pendokumentasian Asuhan Keperawatan Unit Rawat Inap RS M.H Thamrin Purwakarta.

Yulianti. (2011). Hubungan Tingkat Pengetahuan Perawat dengan Penerapan Universal Precaution Pada Perawat di Bangsal Rawat Inap Rumah Sakit PKU Muhammadiyah Yogyakarta. Jurnal Kesehatan Masyarakat Volume 5 No.2.

Zega, Y. (2019). Gambaran Pengetahuan Perawat Tentang Early Warning Scoring System di Ruangan Rawat Inap RIC RSUP Haji Adam Malik.

Ziliwu, H. J., \& Abdu, S. (2014). Buku Ajar Metodologi dan Riset Keperawatan. Takalar: Pustaka As Salam.

Zuhri, M., \& Nuramalia, D. (2018). Pengaruh Early Warning System Terhadap Kompetensi Perawat: Literatur Review. 